\title{
Dummy Decal: Contemporary Ceramics and Endless Decorative Creative Work
}

\section{Dummy Decal: Dekorasi Tanpa Batasan bagi Industri Seramik Moden dan Karya Kreatif}

\author{
Zulkarnian Hassan, Noor Ashraf Noor Othman, Haslinda Md Nazri \& Yasmeen Arni Jr. Jasni Adie \\ Fakulti Seni Lukis dan Seni Reka \\ Universiti Teknologi MARA Cawangan Perak Kampus Seri Iskandar, \\ 32610 Seri Iskandar, Perak, MALAYSIA. \\ zulka246@uitm.edu.my
}

Published: 7 September 2018

\begin{abstract}
Regardless of the type of product or the differences in its basic elements, the product graphic is synonymous with high beauty, uniqueness, and precision. It is parallel with the beautiful ornaments that adorn the surface of the ceramic product, which originate from diverse civilizations and reflect the maker's creative inspiration. The decal is based on the most advanced and widely used ceramic decoration techniques in Europe and China, which serves as an inspiration for the rest of the globe when it comes to putting decoration to their products. Whichever is the case, the manufacturing and distribution expenses of decal decoration techniques are considerable, needing extensive preparation and execution to provide a high-quality result. As a result, the invention of the 'Dummy Decal' decoration process has enabled manufacturers of ceramic products to maintain a consistent level of output while adding differentiation to their designs. Water Based Inkjet Water Transfer Paper is a fresh source of inspiration for creative items and ceramic works. With a modest access fee and the ability to purchase, this decoration serves as a magnet for contemporary products and creative works. This article can be used as a guide and resource for small and medium-sized businesses, as well as individuals, to assist them in developing their creative thinking when it comes to marketing their organic products.
\end{abstract}

Keyword: Ceramics, dummy decals, unique products, and décor

\begin{abstract}
ABSTRAK
Produk seramik amat sinonim dengan keindahan, keaslian dan ketelitian yang tinggi tanpa mengira jenis produk mahupun perbezaan bahan asasnya. Begitu juga dengan hiasan dekorasi yang melitupi permukaan produk seramik yang lahir dari pelbagai budaya dan ilham kreatif pembuatnya. Decal antara teknik hiasan dekorasi seramik paling unggul dan popular di negara Eropah dan China bahkan menjadi inspirasi kepada seluruh dunia dalam mengaplikasi dekorasi tersebut bagi produk keluaran mereka. Walaubagaimanapun, kos penghasilan dan peralatan bagi teknik dekorasi dekal adalah tinggi dan memerlukan kemahiran serta ketelitian sepenuhnya untuk menghasilkan sesuatu produk yang sempurna. Sedari itu, inovasi teknik dekorasi 'Dummy Decal' telah memberi peluang kepada pengusaha produk seramik dalam mengekalkan tahap keluaran dan memberi kelainan dalam rekaan mereka. Ciptaan Water Based Inkjet Water Transfer Paper memberi inspirasi baharu dalam produk kreatif dan karya seramik kreatif. Dengan kos penghasilan yang rendah dan mampu beli, dekorasi ini menjadi tarikan bagi produk moden mahupun karya kreatif. Artikel yang dihasilkan ini dapat dijadikan panduan dan saluran kepada pengusaha baharu mahupun sedia ada untuk meningkatkan pengeluaran kreatif dalam mempromosikan produk seramik mereka.
\end{abstract}

Keyword: Seramik, Dummy Decal, Produk Kreatif, Dekorasi

eISSN: 2550-214X (C) 2018. The Authors. Published for Idealogy Journal of Arts and Social Science by UiTM Press. This is an Open Access article distributed under the terms of the Creative Commons Attribution-NonCommercial-NoDerivatives License (http://creativecommons.org/licenses/by-nc-nd/4.0/), which permits non-commercial re-use, distribution, and reproduction in any medium, provided the original work is properly cited, and is not altered, transformed, or built upon in any way. 


\section{PENDAHULUAN}

Dekorasi dalam bidang seramik dapat dibahagikan kepada beberapa keadaan kumpulan iaitu sebelum bakar, sebelum licau dan selepas licau. Dekorasi seramik merupakan hiasan, corak, atau rekaan tertentu di atas permukaan produk (John, 1990). Teknik dekorasi yang popular digunakan adalah dari kumpulan dekorasi selepas licau kerana proses pengendalian produk yang lebih mudah dan tahap risiko pecah yang rendah. Antara teknik dekorasi yang diaplikasi ke atas permukaan produk seramik selepas licau adalah seperti cetakan terus, cetakan digital, enamel, luster, cetakan sutera saring (decal screen printing), dan cetakan terus stensil fotografi (Duncan, 2012). Walaubagaimanapun, setiap peralatan dan bahan yang diperlukan bagi setiap teknik dekorasi ini adalah berbeza serta melibatkan kos yang tinggi. Bagi pengilang produk seramik di Malaysia, mereka tidak menanggung kos pembuatan produk seramik yang tinggi kerana pembelian bahan dilakukan secara pukal yang mampu menjimatkan kos operasi mereka. Namun, bagi pengusaha produk seramik dalam kategori usahawan kecil dan sederhana, persaingan hebat dari industri seramik besar boleh mengakibatkan kerugian pada hasil keluaran produk mereka hanya kerana kos pembelian bahan yang mahal untuk mendekorasi produk.

Dalam bidang seramik, terma decal tidak asing bagi pengusaha mahupun pengeluar produk tempatan kerana ia memberi keistimewaan dan tambah nilai bagi sesuatu produk keluaran mereka. Motif khusus pada sesuatu permukaan produk boleh menjadikan produk tersebut menonjol di kalangan pasarannya (Anthony, 2010). Decal merupakan lapisan cetakan dakwat seramik menggunakan sutera saring atau litografi yang dipindahkan ke atas permukaan kertas, disaluti dengan varnish, dipindahkan ke permukaan produk dan melalui suatu proses pembakaran dan ianya bersifat kekal (John, 1990). Dekorasi decal terhasil melalui suatu proses yang panjang dan melibatkan penggunaan bahan serta peralatan yang khusus bagi menghasilkannya. Tempoh masa yang diperuntukkan bagi setiap kepingan dekorasi ini juga adalah lama dan memerlukan kemahiran yang tinggi untuk mendapatkan hasil yang kemas atau corak yang jelas.

Decal secara umumnya berfungsi sebagai dekorasi pada permukaan seramik, membantu menutupi kecacatan pada permukaan seramik, serta menambah nilai estetika sesuatu produk seramik. Kebanyakan decal komersial di pasaran perlu dibakar pada suhu tinggi (Susan, 2012). Dengan kos bahan enamel (pewarna seramik) yang agak mahal, melibatkan proses yang panjang serta penggunaan peralatan yang pelbagai, ia menjadi pertimbangan bagi pengusaha seramik ( IKS) untuk menggunakan teknik tersebut. Kerana permasalahan yang timbul, kini kaedah dekorasi seramik telah beralih kepada teknik baharu yang lebih pantas dan efisyen.

Malaysia secara tidak langsung turut menerima tempias terhadap lambakan produk seramik dari China yang menggunakan teknik dekorasi ini. 'Dummy Decal' merupakan teknik aplikasi baharu yang diinovasikan untuk memberi kemudahan kepada pengusaha produk seramik secara sederhana dalam usaha meningkatkan tahap pengeluaran mereka. Dengan kos yang murah, bahan ini mudah didapati secara dalam talian mahupun dari pusat jualan bahan mentah dan peralatan seramik.

\section{KEUNIKAN DEKORASI DUMMY DECAL}

Inovasi kertas dekorasi ini telah diperkenalkan oleh negara Eropah dan ia lebih dikenali dengan nama Water Based Inkjet Water Transfer Paper. Ia merupakan antara inisiatif baharu yang bersifat mampu beli. Kos serta peralatan yang diperlukan juga mudah diperolehi disamping proses yang ringkas dan tidak memerlukan kemahiran yang tinggi untuk mengendalikan teknik dekorasi ini. Proses dummy decal ini mempunyai sedikit perbezaan dengan decal skrin sutera saring dari segi kos bahan, peralatan, operasi dan hasilnya. Kualiti yang dihasilkan melalui dekorasi ini adalah setara dengan dekorasi decal sutera saring, namun tahap ketahanan dan jangkamasa penggunaannya tidak dapat menandingi decal skrin sutera saring yang bersifat kekal. 


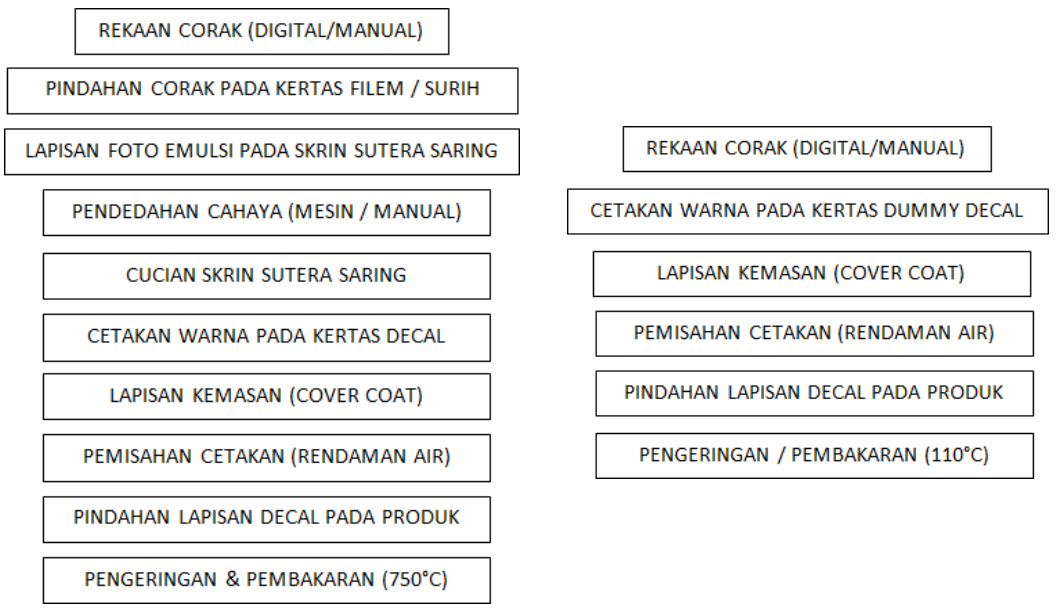

\section{Rajah 1: Perbandingan Proses dekorasi Decal dan Dummy Decal}

Merujuk kepada perbezaan pada Rajah 1, proses asas decal melibatkan sepuluh (10) langkah kerja dari proses lakaran rekaan sehingga ke proses akhir iaitu pembakaran. Bagi dekorasi dummy decal pula hanya enam (6) langkah diperlukan dengan tidak melibatkan aktiviti seperti cetakan pada sutera saring, penggunaan lapisan foto emulsi dan penggunaan mesin pendedahan cahaya (exposed machine). Selain itu, suhu maksima pembakaran dummy decal adalah $110^{\circ} \mathrm{c}$ berbanding decal $750^{\circ} \mathrm{c}$. Proses pemanasan dekorasi ini hanya boleh dilakukan dengan menggunakan peralatan asas seperti oven pembakar. Keistimewaan lain bagi teknik dummy decal ini ialah tidak perlu dibakar jika produk yang dihasilkan berfungsi sebagai produk hiasan semata, tetapi sekadar mengeringkannya di bawah cahaya matahari untuk selama tiga (3) hari berturut sebelum produk tersebut digunakan atau dibungkus untuk jualan.

Peralatan yang diperlukan bagi dekorasi dummy decal adalah seperti kertas water based inkjet transfer water paper, pencetak inkjet, clear coat(semburan) dan oven pembakar. Kertas dummy decal adalah berbeza dengan kertas decal iaitu kertas decal merupakan sejenis kertas yang berasaskan lapisan minyak atau air manakala kertas dummy decal pula berasaskan air.

Terdapat dua (2) jenis kertas dummy decal iaitu transparensi dan putih. Kedua-dua kertas dekorasi ini memberi kesan yang berbeza pada imej atau corak yang dicetak ke atasnya. Fungsi serta hasil produk yang dikehendaki mempengaruhi pemilihan jenis kertas dummy decal ini. Sebagai contoh, jika produk seramik mempunyai warna, adalah sesuai menggunakan kertas dummy putih, manakala jika produk seramik putih lebih sesuai menggunakan kertas transparensi. Perbezaan tersebut memberi kemudahan serta keistimewaan pada teknik dekorasi ini walaupun kos bagi kedua- dua kertas dummy ini adalah sama. Oleh sebab itu, inovasi dekorasi ini menjadi pilihan bagi pengusaha produk cenderahati seramik dalam menghasilkan produk unik dan berbeza kerana kos penghasilannya yang ringkas dan menjimatkan (Zulkarnian, 2015).

\section{PROSES PENGHASILAN DEKORASI DUMMY DECAL}

Dekorasi secara dummy decal tidak memerlukan proses yang rumit malah mampu dihasilkan dalam tempoh $1 \mathrm{jam}$. Proses utama melibatkan pemilihan tema dan konsep rekaan. Terdapat dua (2) jenis kaedah yang boleh digunakan untuk menghasilkan corak atau imej yang dikehendaki. Kaedah pertama adalah melalui lakaran manual pada kertas lukisan. Setelah selesai lakaran awal, imej atau corak tersebut diwarnakan dengan menggunakan sumber media seperti pensil warna, poster warna, magic pen, marker, kurecolor mahupun sebarang jenis pewarna yang diingini. Proses berikutnya adalah menyunting rekaan menggunakan peranti komputer. Kertas lukisan asal perlu diimbas (scanner) atau mengambil foto rekaan (menggunakan kamera) untuk dipindahkan ke dalam aplikasi komputer. Perisian yang boleh digunakan untuk proses suntingan rekaan adalah seperti Adopt Photoshop atau Adobe Illustrator. Perisian lain juga boleh digunakan tertakluk kepada keperluan atau kemahiran pereka. Proses suntingan ini melibatkan penstrukturan semula pola warna rekaan, saiz rekaan, kontra 
warna atau melakukan manipulasi pada imej asal mengikut kreativiti pereka.

Bagi kaedah kedua pula, imej atau corak dari sumber internet atau fotografi yang diambil terus dan diolah menerusi aplikasi komputer. Proses suntingan imej atau corak rekaan adalah sama seperti kaedah pertama. Hasil suntingan tersebut kemudian disimpan mengikut keperluan format kertas atau mesin cetakan (printer inkjet) atau bergantung kepada saiz kertas dummy decal yang digunakan. Kebiasaanya kertas dummy decal ini boleh didapati dalam saiz A4 dan A3. Menjadi tanggungjawap dan kreativiti pereka untuk menyesuaikan saiz kertas dekorasi ini mengikut rekaan dan saiz produk.
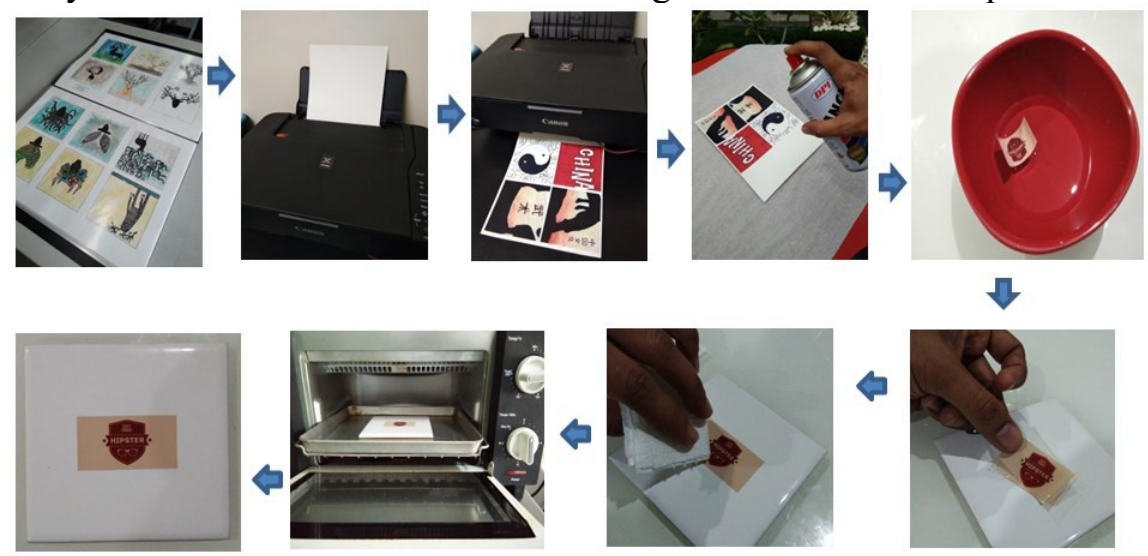

Ilustrasi 1: Proses kerja dekorasi Dummy Decal

Proses berikutnya adalah cetakan rekaan dekorasi ke atas kertas dummy decal melalui mesin cetakan jenis inkjet ink dye based. Oleh kerana permukaan kertas dummy ini disaluti dengan lapisan khas yang berasaskan air (bersifat glossy), cetakan yang dibuat perlu dikeringkan sebentar untuk memastikan dakwat cetakan tersebut kering sebelum proses berikut boleh diteruskan. Warna hasil dari proses cetakan tersebut adalah berdasarkan kepada kualiti dakwat mesin cetakan yang digunakan. Tempoh pengeringkan dianggarkan sekitar 3 minit. Proses seterusnya adalah melapiskan bahan pelindung (varnish) dan pemisah bagi dakwat cetakan digital tersebut. Penyembur transparensi (spray clear) digunakan dalam teknik dekorasi dummy decal ini. Semburan dibuat meliputi keseluruhan ruang rekaan dan perlu diulangai sekurang-kurangnya 2 lapisan atau maksima 4 lapisan mengikut keperluan. Untuk kesan optimum, semburan perlulah konsisten dan menutupi keseluruhan ruang rekaan bagi memastikan pindahan rekaan dapat dilakukan dengan sempurna tanpa merosakkan imej atau corak rekaan. Faktor cuaca dan angin turut diambil kira bagi memastikan proses semburan berjalan lancar. Semburan transparensi tersebut bergantung kepada jenisnya. Terdapat beberapa jenis semburan yang berbeza di pasaran seperti semburan outdoor, indoor, atau quick dry. Kualiti bagi jenis-jenis semburan ini adalah sama kecuali tempoh masa pengeringan yang berbeza.

Setelah selesai proses semburan, kertas dummy decal perlu dipotong mengikut saiz atau bentuk rekaan yang ditetapkan. Kepingan rekaan tersebut direndamkan ke dalam air biasa selama 30 hingga 60 saat bergantung kepada saiz rekaan. Jika rendaman yang dilakukan melebihi tempoh yang ditetapkan, kualiti rekaan dan lapisan khas pada kertas dummy tersebut akan terhakis sehingga menyebabkan gam lapisan kepingan menjadi haus. Dalam tempoh masa 30 saat itu, lapisan cetakan bersama semburan pemisah akan terpisah dari kertas dummy decal. Keadaan lapisan cetakan tersebut bersifat seperti jelly sticker yang amat lembut dan perlu dikendalikan dengan cermat untuk mengelakan kerosakan padanya. Setelah lapisan tersebut terpisah, ia dipindahkan ke atas permukaan produk seramik dengan segera. Proses nyah-air di bawah lapisan cetakan tersebut dilakukan dengan teliti menggunakan alat khas sekuji atau rubber kidney (Josie, 2007) atau kain lembap. Bagi memastikan kualiti dekorasi yang baik, kesan tompokan air atau liang udara perlu dikeluarkan di bawah lapisan cetakan dummy. Jika tidak dilakukan sebaik mungkin, kesan gelembung udara akan terbentuk semasa proses pengeringan dan pembakaran dilakukan dan mengakibatkan kecacatan pada dekorasi.

Proses akhir bagi dekorasi dummy decal adalah pengeringan dan pembakaran produk ke dalam oven. Suhu yang ditetapkan adalah antara $100^{\circ} \mathrm{c}$ hingga $110^{\circ} \mathrm{c}$. Suhu melebihi had disyorkan akan 
menyebabkan kerosakan pada permukaan rekaan dekorasi. Kaedah lain melalui pengeringan di bawah cahaya matahari selama 3 hari. Hasil yang diperolehi dari teknik dummy decal ini lebih kemas dan boleh dilihat terus tanpa perlu menunggu masa untuk pembakaran. Kerana aspek keistimewaan inilah yang membuatkan dekorasi jenis ini menjadi pilihan di kalangan pengusaha tempatan.

Dengan proses kerja yang mudah, setara dan praktikal, ramai pereka kini menggunakan kaedah dekorasi yang ringkas (Beth, 2009) dan penggunaan dekorasi dummy decal ini tidak terhad kepada produk seramik lagi, malah kini ia telah berkembang selari dengan perkembangan teknologi semasa.
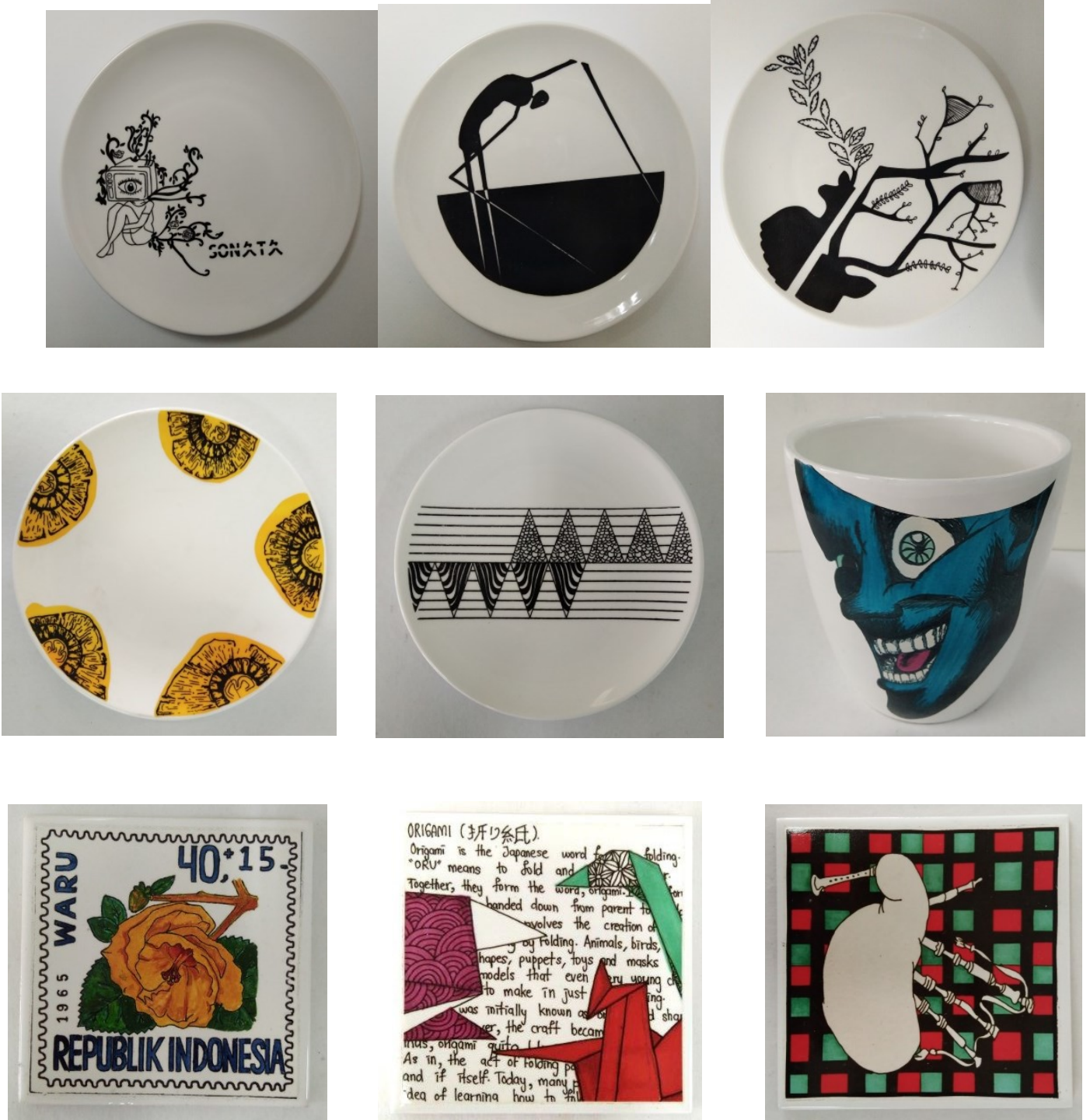

Ilustrasi 2: Produk Seramik yang menggunakan aplikasi Dekorasi Dummy Decal

\section{KEPELBAGAIAN PRODUK MELALUI DEKORASI DUMMY DECAL}

Antara produk yang menjadi pilihan pengusaha untuk mengaplikasi teknik dekorasi dummy decal adalah seperti mug, fridge magnetic, keychain, plaque, hiasan dinding (jubin) serta produk kreatif seperti bentuk binatang, rumah, kereta dan lain-lain lagi. Proses kerja yang mudah serta mampu diaplikasi ke atas semua bentuk permukaan produk seramik termasuk mendatar atau yang bersatah. Keunikan inilah menjadikan sesebuah seramik itu bernilai serta mempunyai potensi komersil yang tinggi untuk bersaing dengan produk lain yang berada dipasaran. 
Water based transfer inkjet water paper ini juga boleh diaplikasi ke atas permukaan lain yang licin seperti plastik, kayu, besi dan kaca. Proses penghasilan dekorasi ini adalah sama seperti dekorasi pada permukaan produk seramik. Dalam bidang Seni Halus, pengenalan kepada teknik dekorasi ini menjadi inspirasi kepada pengkarya seni arca khususnya yang menggunakan bahan tanah liat dalam ekspresi karya mereka. Rekaan dekorasi yang berbentuk abstrak dan kompleks dapat dihasilkan mengikut konsep karya diingini. Tiada istilah mustahil dalam dekorasi dummy decal ini. Bagi pereka bidang Grafik pula, penggunaan kertas pelekat sebagai media terjemahan idea kreatif mereka untuk tujuan pembungkusan produk juga boleh digantikan dengan kertas dummy decal. Namun begitu, ia tertakluk kepada media selain dari kain dan kertas.

Kertas dekorasi dummy decal ini mempunyai ketahanan dari segi kualiti warna dan imej pada permukaan produk. Ia juga dipengaruhi oleh faktor cara penggunaan, lokasi kegunaan produk serta kesempurnaan proses penghasilan teknik ini dihasilkan. Jadi tidak hairanlah penggunaan teknik ini menjadi trend terkini dalam pemasaran produk seramik mahupun produk lain.
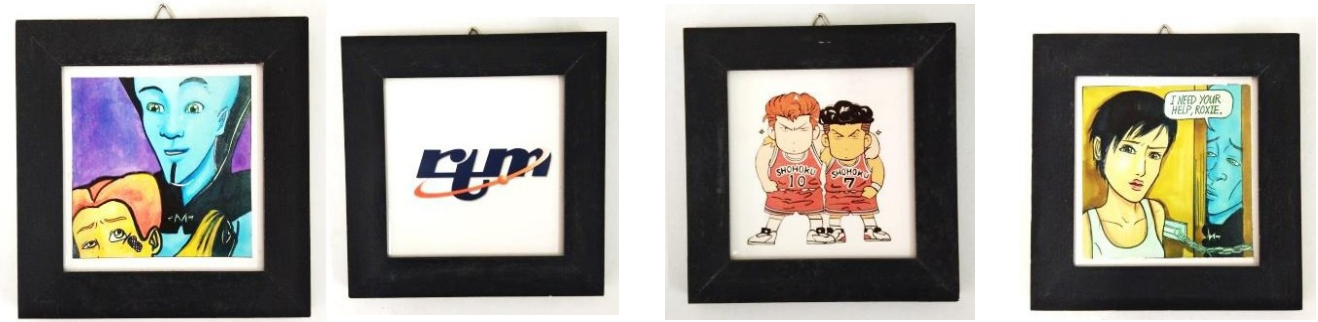

Ilustrasi 3: Contoh Hasil Produk Jualan untuk komersial

\section{KESIMPULAN}

Dekorasi memainkan peranan penting dalam sesuatu hasil produk dengan memberi kelaian, mencetus identiti serta sebagai nilai tambah. Kewujudan pelbagai teknik dekorasi memberi peluang kepada kelompok tertentu khususnya mereka yang melibatkan diri dalam dunia perusahaan secara mikro. Ruang yang ada serta kemahiran yang diperolehi mampu memacu industri kecil sederhana ini ke peringkat global sekaligus bersaing dengan industri lain di pasaran terbuka. Pelbagai inisiatif telah disediakan oleh pihak kerajaan dan NGO untuk membantu usahawan meningkatkan taraf pendapatan mereka. Aspek inovasi dalam perniagaan, pengurusan dan pengendalian produk perlu dipertingkatkan untuk kemajuan masing-masing.

\section{BIBLIOGRAFI}

Anthony Q. (2010). The Ceramic Design Course: Principles, Practices, Techniques. United Kingdom: Thames \& Hudson

Duncan H, Anthony Q. (2012). The Workshop Guide to Ceramic. United Kingdom: Thames \& Hudson

Fifth Edition. London: Laurence King Publishing Ltd.

John W. C. (1990). Studio Ceramic Dictonary. Califonia: Falcon Company Publishers

Josie W. (2007). The Complete Practical Potter. London: Hermes House. Beth G., Bill F. (2009). Print-

Making: A Complete Guide to Materials and Processes. London: Laurence King Publishing Ltd.

Susan P., Jan P. (2012). The Craft and Art of Clay: A Complete Potter's Handbook,

Zulkarnian H. (2015). Pameran Diploma Seni Lukis dan Seni Reka Seramik (Buku Pameran). Perak:

FSSR Publication 